\title{
Diagnostic accuracy of $T$ stage of gastric cancer from the view point of application of laparoscopic proximal gastrectomy
}

\author{
KEITA KOUZU, HIRONORI TSUJIMOTO, SHUICHI HIRAKI, \\ SHINSUKE NOMURA, JUNJI YAMAMOTO and HIDEKI UENO \\ Department of Surgery, National Defense Medical College, Tokorozawa, Saitama 359-8513, Japan
}

Received August 18, 2017; Accepted February 22, 2018

DOI: $10.3892 / \mathrm{mco} .2018 .1616$

\begin{abstract}
The preoperative diagnosis of T stage is important in selecting limited treatments, such as laparoscopic proximal gastrectomy (LPG), which lacks the ability to palpate the tumor. Therefore, the present study examined the accuracy of preoperative diagnosis of the depth of tumor invasion in early gastric cancer from the view point of the indication for LPG. A total of 193 patients with cT1 gastric cancer underwent LPG with gastrointestinal endoscopic examinations and a series of upper gastrointestinal radiographs. The patients with $\mathrm{pT} 1$ were classified into the correctly diagnosed group (163 patients, $84.5 \%$ ), and those with pT2 or deeper were classified into the underestimated group (30 patients, $15.5 \%$ ). Factors that were associated with underestimation of tumor depth were analyzed. Tumor size in the underestimated group was significantly larger; the lesions were more frequently located in the upper third of the stomach and were more histologically diffuse, scirrhous, with infiltrative growth, and more frequent lymphatic and venous invasion. For upper third lesions, in univariate analysis, histology (diffuse type) was associated with underestimation of tumor depth. Multivariate analysis found that tumor size $(\geq 20 \mathrm{~mm})$ and histology (diffuse type) were independently associated with underestimation of tumor depth. gastric cancer in the upper third of the stomach with diffuse type histology and $>20 \mathrm{~mm}$ needs particular attention when considering the application of LPG.
\end{abstract}

\section{Introduction}

Laparoscopic proximal gastrectomy (LPG) has been established as a minimally invasive and function-preserving surgery for early gastric cancer located in the upper third

Correspondence to: Professor Hironori Tsujimoto, Department of Surgery, National Defense Medical College, 3-2 Namiki, Tokorozawa, Saitama 359-8513, Japan

E-mail: tsujihi@ndmc.ac.jp

Key words: early gastric cancer, preoperative diagnosis, laparoscopic gastrectomy of the stomach $(1,2)$. The indications for LPG are usually determined based on the preoperative evaluation of tumor stage. However, the accuracy of preoperative evaluation of tumor depth for early gastric cancer is reported to be only $92.2-96.4 \%(3,4)$. In addition, patients who undergo proximal gastrectomy and have the depth of tumor underestimated preoperatively have a higher frequency of recurrence (5). Therefore, adequate preoperative evaluation for gastric cancer staging is essential to develop an individualized treatment with minimal lymphadenectomy and gastrectomy.

Advance in the field of nanotechnology has also been involved in cancer diagnosis and therapy which may applicable for treating early gastric cancer $(6,7)$. However, these techniques are developing, and we are waiting for the clinical data comparing current surgical treatment.

In this study, we evaluated the accuracy of preoperative diagnosis of tumor depth in patients with early gastric cancer located in the upper third of the stomach in order to safely select optimal candidates for LPG.

\section{Patients and methods}

Patients. One hundred ninety-three patients who were diagnosed with clinical (c) T1 gastric cancer underwent laparoscopic gastrectomy at National Defense Medical College Hospital from 2009 to 2015. Tumor invasion of gastric cancer conformed to TNM classification. Laparoscopic gastrectomy has been performed for cases with tumor invasion up to T3 regardless of lymph node metastasis in our department. Laparoscopic proximal gastrectomy was indicated in whom tumor invasion was preoperatively evaluated to be cT1, otherwise total gastrectomy was employed. The tumor depth was evaluated by the findings of gastrointestinal endoscopic examinations and upper gastrointestinal radiograph series. For each case, three experts who had more than 10 years of experience in the performance of laparoscopic gastrectomy were included for evaluation of tumor depth. No patient underwent preoperative endoscopic ultrasound (EUS) during this period.

We defined patients who were diagnosed with pathological (p) T1 as the correct group and those diagnosed with pT2 or deeper as the underestimated group. The clinical and pathological records of the patients were retrospectively evaluated 
for tumor size, location, depth, gross type, histology (Lauren's classification), lymphatic invasion, and venous invasion by confirming the pathological report. We investigated which pathological factors might have caused an underestimation. The clinical, pathological, and final findings of the patients were described according to the third English edition of the Japanese Classification of Gastric Carcinoma (JCGC), which was edited by the Japanese Gastric Cancer Association (8). The study protocol was reviewed and approved by the Institutional Review Board at the National Defense Medical College, and written informed consent was obtained from every patient before the study.

Statistical analysis. The statistical analyses were performed using the software package JMP pro 11.0.0 (SAS Institute, Cary, NC,USA). The data are expressed as the mean \pm standard error. Statistical analyses were performed using the Mann-Whitney U test, chi-square test, or Fisher's exact test, whichever was considered appropriate. Multivariate analysis was performed using step-wise selection according to the previous report (9). In brief, we select the largest variable selection statistic for the log hazard ratio from all the variables at first. Variables are fetched according to importing criteria. Every time one variable is fetched, it checks whether there is one that fulfills the same eviction criterion as the decreasing method among the already captured variables, if there is any, retrieves that variable and continues fetching the variable further. Then, when there are neither variables to fetch nor variables to be driven out, the selection of variables is ended. This method has a feature of choosing a small number of variables that contribute to the log hazard ratio at a high ratio. P-values of $<0.05$ were considered statistically significant.

\section{Results}

The demographic data of patients with cT1 gastric cancer who underwent laparoscopic gastrectomy are shown in Table I. One hundred and sixty-three $(84.5 \%)$ patients were correctly diagnosed and 30 patients $(15.5 \%)$ were underestimated. There was no difference in the age, sex, body mass index (BMI), tumor circumference, or gross type of tumor between the 2 groups. The underestimated group had a significantly larger tumor size and a higher incidence of upper third tumor location, diffuse type, and scirrhous type of stroma than the correct group. In addition, the underestimated group had a higher frequency of INFc growth pattern and more extensive lymphatic and venous invasion.

We examined preoperative clinical factors that may affect underestimation of tumor depth by univariate and multivariate analyses (Table II). Univariate analysis revealed that the tumor size $(\geq 20 \mathrm{~mm})$ and the tumor location (upper third of the stomach) were associated with the underestimation of tumor depth. In addition, multivariate analysis revealed that the tumor size ( $\geq 20 \mathrm{~mm}$ ), the tumor location (upper third of the stomach), and histology (diffuse type) were independently associated with the underestimation of tumor depth.

Next, we evaluated the clinicopathological findings among patients whose tumor was located in the upper third of the stomach (Table III). There was no difference in the age, sex, type of operation, BMI, tumor circumference, or gross type of tumor between the groups. Univariate analysis revealed that histology (diffuse type) was associated with the underestimation of tumor depth. In addition, multivariate analysis using step-wise selection revealed that the tumor size $(\geq 20 \mathrm{~mm})$ and histology (diffuse type) were independently associated with the underestimation of tumor depth (Table IV).

We divided the patients into four groups according to the combination of histology and tumor size. All patients with intestinal type of histology and small tumors $(<20 \mathrm{~mm})$ were correctly diagnosed, whereas $75 \%$ of patients with a diffuse type of histology and a larger tumor ( $\geq 20 \mathrm{~mm}$ ) were underestimated (Table V).

\section{Discussion}

In Japan, standard surgeries for gastric cancer are total gastrectomy or distal gastrectomy with D2 lymphadenectomy. However, the pathological analyses of resected specimens have shown that lymph node involvement occurs in fewer than $20 \%$ of patients with early gastric cancer in Japan $(3,10)$ and such standard surgeries can cause persistent functional disorders and significantly reduce a patient's quality of life. According to the Japanese guidelines for gastric cancer, we can apply limited resections such as proximal gastrectomy for T1 cancer $(11,12)$. Diagnosis of the depth of gastric cancer is essential for determining the therapeutic strategy because the tumor depth correlates with lymph node metastasis (11). In this study, we examined the accuracy of the evaluation of depth of tumor invasion in early gastric cancer and we evaluated indications for LPG, and the study revealed the following 2 important findings.

First, the frequency of underestimation was markedly increased in cases with diffuse type histology. Our findings support and extend the previous reports indicating that accurate preoperative diagnosis of tumor depth is generally more difficult in diffuse type gastric cancer than in intestinal type gastric cancer (13). Kim et al reported that histologically undifferentiated types of tumors were associated with lower diagnostic accuracy of endoscopic assessments of the depth of tumor invasion as compared to differentiated types of tumors (14). The reason why the diffuse type tends to be underestimated is that diffuse-type cancer presents with infiltrative growth under the mucosa whereas intestinal type cancer presents with expansive growth. This finding also suggests a reason why the tumor size is larger in the underestimated group.

Second, clinically early gastric cancer in the upper third of the stomach has a tendency to be underestimated. Diffuse type of tumor commonly derives from the fundic gland. We found that $27 \%(10 / 37)$ of cases were underestimated in upper third cT1 gastric cancer. This suggests that an inadequate procedure, LPG, may affect $27 \%$ of patients because LPG is not indicated for cT2 gastric cancer.

To improve the accuracy of diagnosis of tumor depth, EUS may be effective. A meta-analysis of 46 studies demonstrated the sensitivity and specificity of EUS to distinguish T1 vs. T2 were 0.85 (95\% CI 0.78 to 0.91 ) and 0.90 (95\% CI 0.85 to 0.93 ), respectively (15). However, EUS requires advanced techniques for evaluating early gastric cancer or gastric cardia cancer (16), and it is reported that EUS frequently underestimates tumor depth in cases located in the upper third of the stomach (17). 
Table I. Demographic data of patients with cT1 gastric cancer.

\begin{tabular}{|c|c|c|c|}
\hline & Correct group $(n=163)$ & Underestimate group $(n=30)$ & P-value \\
\hline Age (years) & $68.0 \pm 10.2$ & $66.0 \pm 13.1$ & 0.777 \\
\hline Male/female & $124 / 39$ & $21 / 9$ & 0.479 \\
\hline Body mass index & $22.4 \pm 3.1$ & $22.0 \pm 2.5$ & 0.596 \\
\hline Tumor size $(\mathrm{mm})$ & $31.8 \pm 21.0$ & $46.2 \pm 31.7$ & 0.012 \\
\hline \multicolumn{4}{|l|}{ Tumor location } \\
\hline Upper third & $27(16.6 \%)$ & $10(33.3 \%)$ & \multirow[t]{3}{*}{0.047} \\
\hline Middle third & $60(36.8 \%)$ & $12(40.0 \%)$ & \\
\hline Lower third & $76(46.6 \%)$ & $8(26.7 \%)$ & \\
\hline \multicolumn{4}{|l|}{ Circumferences } \\
\hline Ant/post & $37 / 61$ & $5 / 15$ & 0.278 \\
\hline Gre/less & $29 / 80$ & $4 / 18$ & 0.406 \\
\hline \multicolumn{4}{|l|}{ Tumor depth } \\
\hline pT2 & & $17(56.7 \%)$ & \\
\hline pT3 & & $11(36.7 \%)$ & \\
\hline pT4 & & $2(6.7 \%)$ & \\
\hline \multicolumn{4}{|c|}{ Lymph nodal metastasis } \\
\hline $\mathrm{cNO}$ & $161(84.7 \%)$ & $29(100 \%)$ & \multirow[t]{2}{*}{0.493} \\
\hline $\mathrm{cN} 1$ & $3(15.3 \%)$ & $0(0 \%)$ & \\
\hline \multicolumn{4}{|l|}{ Gross type } \\
\hline Elevated & $47(28.7 \%)$ & $5(31.3 \%)$ & \multirow[t]{3}{*}{0.969} \\
\hline Flat & $12(7.3 \%)$ & $1(6.3 \%)$ & \\
\hline Depressed & $105(64.0 \%)$ & $10(62.5 \%)$ & \\
\hline \multicolumn{4}{|l|}{ Histology } \\
\hline Intestinal type & $115(70.6 \%)$ & $15(50.0 \%)$ & \multirow[t]{2}{*}{0.027} \\
\hline Diffuse type & $48(29.5 \%)$ & $15(50.0 \%)$ & \\
\hline \multicolumn{4}{|l|}{ Stroma } \\
\hline Int & $46(66.7 \%)$ & $13(44.8 \%)$ & \multirow[t]{3}{*}{0.005} \\
\hline Med & $13(18.8 \%)$ & $3(10.3 \%)$ & \\
\hline Sci & $10(14.5 \%)$ & $13(44.8 \%)$ & \\
\hline \multicolumn{4}{|l|}{ Infiltrative growth } \\
\hline $\mathrm{a}$ & $11(15.9 \%)$ & $1(3.5 \%)$ & \multirow[t]{3}{*}{$<0.001$} \\
\hline $\mathrm{b}$ & $48(69.6 \%)$ & $13(44.8 \%)$ & \\
\hline $\mathrm{c}$ & $10(14.5 \%)$ & $15(51.7 \%)$ & \\
\hline \multicolumn{4}{|c|}{ Lymphatic invasion } \\
\hline ly $(-)$ & $127(77.4 \%)$ & $8(27.6 \%)$ & \multirow[t]{2}{*}{$<0.001$} \\
\hline ly $(+)$ & $37(22.6 \%)$ & $21(72.4 \%)$ & \\
\hline \multicolumn{4}{|l|}{ Venous invasion } \\
\hline $\mathrm{v}(-)$ & $134(81.7 \%)$ & $7(24.1 \%)$ & \multirow[t]{2}{*}{$<0.001$} \\
\hline $\mathrm{v}(+)$ & $30(18.3 \%)$ & $22(75.9 \%)$ & \\
\hline
\end{tabular}

Data are expressed as the mean $\pm \mathrm{SD}$.

For preoperative diagnosis of the tumor depth in early gastric cancer, it may be necessary to understand the features and limitations of clinical findings completely, especially for lesions located in the upper third of the stomach.

This study has certain limitations. This study was single institutional retrospective design and had relatively small number of patients. In addition, this study included only the patients with cT1 cases who underwent LPG. Thus, it is necessary to conduct a multicenter, prospective, randomized study in order to verify our data.

The preoperative evaluation of the tumor is important in terms of prediction of the lymph node metastasis. In this regard, sentinel node navigation surgery (SNNS) should be promising to evaluate the validity of reduction surgery (18). If the efficacy 
Table II. Univariate and multivariate analysis of the factors that may affect underestimation of tumor depth in cT1 gastric cancer.

\begin{tabular}{|c|c|c|c|c|c|c|}
\hline & \multicolumn{3}{|c|}{ Univariate analysis } & \multicolumn{3}{|c|}{ Multivariate analysis } \\
\hline & Odds ratio & $95 \% \mathrm{CI}$ & P-value & Odds ratio & $95 \% \mathrm{CI}$ & P-value \\
\hline Age (years) & 0.99 & $0.96-1.03$ & 0.697 & & & \\
\hline \multicolumn{7}{|l|}{ Male/female } \\
\hline Male & 0.85 & $0.35-2.17$ & 0.716 & & & \\
\hline Body mass index & 0.95 & 0.82-1.09 & 0.442 & & & \\
\hline \multicolumn{7}{|l|}{ Tumor size } \\
\hline$\geq 20 \mathrm{~mm}$ & 6.09 & $1.74-38.7$ & 0.003 & 6.61 & $1.82-42.9$ & 0.002 \\
\hline \multicolumn{7}{|l|}{ Tumor location } \\
\hline Upper third & 2.67 & $1.09-6.30$ & 0.033 & 3.99 & $1.49-10.8$ & 0.006 \\
\hline \multicolumn{7}{|l|}{ Gross type } \\
\hline Depressed & 0.94 & $0.33-2.87$ & 0.904 & & & \\
\hline \multicolumn{7}{|l|}{ Histology } \\
\hline Diffuse type & 2.19 & $0.98-4.91$ & 0.057 & 2.88 & $1.19-7.20$ & 0.019 \\
\hline
\end{tabular}

Table III. Demographic data of patients with cT1 upper third gastric cancer.

\begin{tabular}{|c|c|c|c|}
\hline & Correct group $(n=27)$ & Underestimated group $(n=10)$ & P-value \\
\hline Age (years) & $71.4 \pm 9.4$ & $71.9 \pm 7.6$ & 0.932 \\
\hline Male/female & $21 / 6$ & $8 / 2$ & 0.884 \\
\hline Body mass index & $22.5 \pm 2.8$ & $22.3 \pm 2.2$ & 0.871 \\
\hline Tumor size (mm) & $32.7 \pm 24.1$ & $44.8 \pm 34.5$ & 0.266 \\
\hline \multicolumn{4}{|l|}{ Tumor size, mm } \\
\hline$>=20$ & $17(63.0 \%)$ & $9(90.0 \%)$ & \multirow[t]{2}{*}{0.110} \\
\hline$<20$ & $10(37.0 \%)$ & $1(10.0 \%)$ & \\
\hline \multicolumn{4}{|l|}{ Operation } \\
\hline Total gastrectomy & $11(40.7 \%)$ & $4(40.0 \%)$ & \multirow[t]{2}{*}{0.968} \\
\hline Proximal gastrectomy & $16(59.3 \%)$ & $6(60.0 \%)$ & \\
\hline \multicolumn{4}{|l|}{ Circumferences } \\
\hline Ant/post & $6 / 9$ & $0 / 6$ & 0.067 \\
\hline Gre/less & $3 / 18$ & $3 / 5$ & 0.168 \\
\hline \multicolumn{4}{|l|}{ Lymph nodal metastasis } \\
\hline $\mathrm{cN} 0$ & $26(96.3 \%)$ & $10(100 \%)$ & \multirow[t]{2}{*}{0.537} \\
\hline $\mathrm{cN} 1$ & $1(2.7 \%)$ & $0(0 \%)$ & \\
\hline \multicolumn{4}{|l|}{ Gross type } \\
\hline Elevated & $11(40.7 \%)$ & $2(40.0 \%)$ & \multirow[t]{3}{*}{0.714} \\
\hline Flat & $3(11.1 \%)$ & $0(0 \%)$ & \\
\hline Depressed & $13(48.2 \%)$ & $3(60.0 \%)$ & \\
\hline \multicolumn{4}{|l|}{ Histology } \\
\hline Intestinal type & $25(92.6 \%)$ & $6(60.0 \%)$ & \multirow[t]{2}{*}{0.017} \\
\hline Diffuse type & $2(7.4 \%)$ & $4(40.0 \%)$ & \\
\hline \multicolumn{4}{|l|}{ Stroma } \\
\hline Int & $13(86.7 \%)$ & $5(50.0 \%)$ & \multirow[t]{3}{*}{0.028} \\
\hline Med & $2(13.3 \%)$ & $1(10.0 \%)$ & \\
\hline Sci & $0(0 \%)$ & $4(40.0 \%)$ & \\
\hline
\end{tabular}


Table III. Continued.

\begin{tabular}{lcc}
\hline & Correct group $(\mathrm{n}=27)$ & Underestimated group $(\mathrm{n}=10)$ \\
\hline Infiltrative growth & & \\
$\mathrm{a}$ & $0(0 \%)$ & $0(0 \%)$ \\
$\mathrm{b}$ & $15(69.6 \%)$ & $5(50.0 \%)$ \\
$\mathrm{c}$ & $0(0 \%)$ & $5(50.0 \%)$ \\
Lymphatic invasion & & \\
ly $(-)$ & $19(70.4 \%)$ & $2(20.0 \%)$ \\
ly $(+)$ & $8(29.6 \%)$ & $8(80.0 \%)$ \\
Venous invasion & & $1(10.0 \%)$ \\
v (-) & $18(66.7 \%)$ & $9(90.0 \%)$ \\
v (+) & $9(33.3 \%)$ & 0.010 \\
\hline
\end{tabular}

Table IV. Univariate and multivariate analysis of the factors that may affect underestimation of tumor depth in cT1 upper third gastric cancer that can be detected before the operation.

\begin{tabular}{|c|c|c|c|c|c|c|}
\hline & \multicolumn{3}{|c|}{ Univariate analysis } & \multicolumn{3}{|c|}{ Multivariate analysis } \\
\hline & Odds ratio & $95 \% \mathrm{CI}$ & P-value & Odds ratio & $95 \% \mathrm{CI}$ & P-value \\
\hline Age (years) & 1.01 & $0.92-1.10$ & 0.879 & & & \\
\hline \multicolumn{7}{|l|}{ Male/female } \\
\hline Male & 1.14 & $0.21-8.91$ & 0.883 & & & \\
\hline Body mass index & 0.98 & $0.70-1.32$ & 0.893 & & & \\
\hline \multicolumn{7}{|l|}{ Tumor size } \\
\hline$\geq 20 \mathrm{~mm}$ & 5.29 & $0.80-105.1$ & 0.087 & 9.46 & $1.04-318.7$ & 0.046 \\
\hline \multicolumn{7}{|l|}{ Gross type } \\
\hline Depressed & 1.16 & $0.23-13.8$ & 0.625 & & & \\
\hline \multicolumn{7}{|l|}{ Histology } \\
\hline Diffuse type & 8.33 & $1.32-71.6$ & 0.024 & 14.01 & $1.69-306.0$ & 0.013 \\
\hline
\end{tabular}

Table V. Association between underestimation of tumor depth in cT1 upper third gastric cancer and histology and tumor size.

\begin{tabular}{lcc}
\hline $\begin{array}{l}\text { Histology, } \\
\text { tumor size }\end{array}$ & $\begin{array}{c}\text { Correct group } \\
(\mathrm{n}=27)(\%)\end{array}$ & $\begin{array}{c}\text { Underestimated } \\
\text { group }(\mathrm{n}=10)(\%)\end{array}$ \\
\hline Intestinal, $<20 \mathrm{~mm}$ & $9(100)$ & $0(0)$ \\
Intestinal, $\geq 20 \mathrm{~mm}$ & $16(72.7)$ & $6(27.3)$ \\
Diffuse, $<20 \mathrm{~mm}$ & $1(50.0)$ & $1(50.0)$ \\
Diffuse, $\geq 20 \mathrm{~mm}$ & $1(25.0)$ & $3(75.0)$ \\
\hline
\end{tabular}

and feasibility of SNNS are demonstrated, the risk of lymph node metastasis will be contracted regardless the preoperative underestimation of the tumor depth.

In conclusion, when considering the application of LPG for clinically early gastric cancer patients, it is important to realize that the diagnostic accuracy of $\mathrm{T}$ stage of early gastric cancer in the upper third of the stomach is low, especially in cases where the tumor has diffuse type histology and is larger than $20 \mathrm{~mm}$.

\section{Acknowledgements}

The authors thank Yoshihisa Yaguchi, Isao Kumano, Risa Takahata, and Hiroyuki Horiguchi from the Department of Surgery, National Defense Medical College, for their contribution to data collection and for their critical revision.

\section{Funding}

No funding was received.

\section{Availability of data and materials}

All data are available on request.

\section{Authors' contributions}

KK and HT contributed to the conception, design and drafting the manuscript. SH, SN, JY and HU substantially contributed to the acquisition and analysis of the work, and revised manuscript critically. All authors read and approved the final manuscript. 


\section{Ethics approval and consent to participate}

All procedures followed were in accordance with the Helsinki Declaration of 1964 and later versions. The study protocol was approved by the Institutional Review Board of the National Defense Medical College.

\section{Consent for publication}

Written informed consent was obtained from every patient before the study.

\section{Competing interests}

The authors declare that they have no competing interests.

\section{References}

1. Kitano S, Adachi Y, Shiraishi N, Suematsu T and Bando T: Laparoscopic-assisted proximal gastrectomy for early gastric carcinomas. Surg Today 29: 389-391, 1999.

2. Nakajima T: Gastric cancer treatment guidelines in Japan. Gastric Cancer 5: 1-5, 2002.

3. Tsujimoto H, Sugasawa H, Ono S, Ichikura T, Yamamoto J and Hase K: Has the accuracy of preoperative diagnosis improved in cases of early-stage gastric cancer? World J Surg 34: 1840-1846, 2010.

4. Yanai H, Matsumoto Y, Harada T, Nishiaki M, Tokiyama H, Shigemitsu T, Tada M and Okita K: Endoscopic ultrasonography and endoscopy for staging depth of invasion in early gastric cancer: A pilot study. Gastrointest Endosc 46: 212-216, 1997.

5. Kim JH, Park SS, Kim J, Boo YJ, Kim SJ, Mok YJ and Kim CS: Surgical outcomes for gastric cancer in the upper third of the stomach. World J Surg 30: 1870-1878, 2006.

6. Wang K, Huang Q, Qiu F and Sui M: Non-viral delivery systems for the application in p53 cancer gene therapy. Curr Med Chem 22: 4118-4136, 2015.

7. Wen R, Banik B, Pathak RK, Kumar A, Kolishetti N and Dhar S Nanotechnology inspired tools for mitochondrial dysfunction related diseases. Adv Drug Deliv Rev 99: 52-69, 2016.
8. Japanese Gastric Cancer Association: Japanese classification of gastric carcinoma: 3rd English edition. Gastric Cancer 14: 101-112, 2011.

9. Armitage P, Berry G and Matthews JNS: Statistical methods in medical research. 4th edition. Blackwell Science LTD, Oxford, pp356-358, 2002.

10. Kunisaki C, Takahashi M, Nagahori Y, Fukushima T, Makino H, Takagawa R, Kosaka T, Ono HA, Akiyama H, Moriwaki Y and Nakano A: Risk factors for lymph node metastasis in histologically poorly differentiated type early gastric cancer. Endoscopy 41: 498-503, 2009.

11. Gotoda T, Yanagisawa A, Sasako M, Ono H, Nakanishi Y, Shimoda T and Kato Y: Incidence of lymph node metastasis from early gastric cancer: Estimation with a large number of cases at two large centers. Gastric Cancer 3: 219-225, 2000.

12. Lee HJ, Kim YH, Kim WH, Lee KU, Choe KJ, Kim JP and Yang HK: Clinicopathological analysis for recurrence of early gastric cancer. Jpn J Clin Oncol 33: 209-214, 2003.

13. Tokunaga M, Hiki N, Fukunaga T, Ohyama S, Yamada K and Yamaguchi T: Better prognosis of T2 gastric cancer with preoperative diagnosis of early gastric cancer. Ann Surg Oncol 16: 1514-1519, 2009.

14. Kim JH, Song KS, Youn YH, Lee YC, Cheon JH, Song SY and Chung JB: Clinicopathologic factors influence accurate endosonographic assessment for early gastric cancer. Gastrointest Endosc 66: 901-908, 2007.

15. Mocellin S and Pasquali S: Diagnostic accuracy of endoscopic ultrasonography (EUS) for the preoperative locoregional staging of primary gastric cancer. Cochrane Database Syst Rev 2: CD009944, 2015.

16. Park CH, Park JC, Chung H, Shin SK, Lee SK and Lee YC: A specific role of endoscopic ultrasonography for therapeutic decision-making in patients with gastric cardia cancer. Surg Endosc 30: 4193-4199, 2016.

17. Tsuzuki T, Okada H, Kawahara Y, Nasu J, Takenaka R, Inoue M, Kawano S, Kita M, Hori K and Yamamoto K: Usefulness and problems of endoscopic ultrasonography in prediction of the depth of tumor invasion in early gastric cancer. Acta Med Okayama 65: 105-112, 2011.

18. Kitagawa Y, Takeuchi H, Takagi Y, Natsugoe S, Terashima M, Murakami N, Fujimura T, Tsujimoto H, Hayashi $\mathrm{H}$, Yoshimizu N, et al: Sentinel node mapping for gastric cancer: A prospective multicenter trial in Japan. J Clin Oncol 31: 3704-3710, 2013. 